\title{
Mast cells in COPD airways: relationship to bronchodilator responsiveness and angiogenesis
}

\author{
Amir Soltani*, Yean Pin Ewe $e^{*+}$, Zhen Sheng Lim*,+, Sukhwinder S. Sohal*, \\ David Reid ${ }^{*}$, Steve Weston*, Richard Wood-Baker* and E. Haydn Walters*,
}

ABSTRACT: We have investigated whether mast cells are associated with bronchodilator responsiveness and airway vascular changes in chronic obstructive pulmonary disease (COPD) airways. We have previously shown that the reticular basement membrane is hypervascular and the lamina propria is hypovascular in COPD.

Bronchial biopsies from 32 COPD subjects, 15 smokers with normal lung function and 17 controls, were immunostained for factor VIII, mast cell tryptase and chymase antibodies. Mast cells in the airway smooth muscle, the reticular basement membrane and the underlying lamina propria were quantitated.

$41 \%$ of COPD subjects had significant bronchodilator responsiveness, but this was not related to smooth muscle mast cell numbers. The reticular basement membrane had greater mast cell density in all groups compared with controls $(p<0.01)$. In this compartment, perivascular mast cell density was related to hypervascularity. Lamina propria mast cell density was increased only in COPD $(p<0.05)$. Perivascular mast cell density in the lamina propria was not related to its decreased vessel density.

Bronchodilator responsiveness in COPD is not related to large airway smooth muscle mast cells of either type; both reticular basement membrane and lamina propria mast cells are increased in COPD patients, and perivascular mast cells may be involved in increased angiogenesis in the reticular basement membrane.

KEYWORDS: Airway remodelling, airway vessels, bronchodilator responsiveness, chronic obstructive pulmonary disease, mast cells

$\mathbf{M}$ ast cells are secretory cells that are replete with granules containing a wide variety of bioactive agents including pro-inflammatory, pro-fibrotic, pro-angiogenic (e.g. vascular endothelial growth factor (VEGF)) and anti-angiogenic factors [1].

Mast cells are thought to contribute to bronchoconstriction, mucus secretion, mucosal oedema, bronchial hyperreactivity (BHR), inflammation, angiogenesis and airway remodelling in asthma [2-5]. In particular, an increase in the number of airway smooth muscle (ASM) layer mast cells has been suggested to be related to asthmatic BHR [3]. Bronchodilator responsiveness (BDR) has been shown to be related to BHR [6] and is probably based on similar underlying mechanisms.

It is generally held that, by definition, airway obstruction in chronic obstructive pulmonary disease (COPD) is irreversible. However, significant
BDR is in fact present in a large subgroup of patients with COPD, although they are mainly screened out from therapeutic studies $[7,8]$. Some investigators have suggested that this BDR feature in COPD is related to "asthma-like" pathology, i.e. an overlap syndrome [9-11]. A substantial number of COPD subjects have been shown to have BHR $[12,13]$ with a significant correlation between BDR and BHR [14]. Therefore, given the relationships between both BHR and BDR in asthma and COPD, it is relevant to examine the smooth muscle layer in COPD airways for the number and type of mast cells, and its relationship to BDR in this setting.

Most cellular mediators can only effectively function close to the cells of origin to effect nearby target cells [3, 15]. We have previously reported hypervascularity in the reticular basement membrane (Rbm) and hypovascularity of the lamina propria (LP) in the airways of current smokers with COPD (S-COPD) and to some
AFFILIATIONS

*Menzies Research Institute, University of Tasmania, Hobart, \#Queensland Institute of Medical Research, Brisbane,

"Mercy Health Victoria, Melbourne, Australia, and

${ }^{+}$Y.P. Ewe and Z.S. Lim worked on aspects of this project for their honours project in the undergraduate Medicine course at University of Tasmania. They are joint-second authors.

CORRESPONDENCE

E.H. Walters

Menzies Research Institute

17 Liverpool Street Hobart TAS 7000

Australia

E-mail: haydn.walters@utas.edu.au

Received:

May 182011

Accepted after revision:

Oct 122011

First published online:

Oct 272011 
extent smokers with normal lung function (S-N) [16]. We questioned whether these vascular changes could be associated with alterations in the number of mast cells in these compartments, especially in close apposition to vessels. We hypothesised that 1) patients with COPD who show BDR have higher mast cell numbers in the ASM layer; and 2) mast cells are increased in the Rbm and decreased in the LP, especially around blood vessels, in current smokers.

\section{METHODS}

We analysed endobronchial airway biopsies from 64 subjects including 17 S-COPD, 15 ex-smokers with COPD (ES-COPD), 15 S-N and 17 healthy nonsmoking controls (H-N) to examine airway wall vascularity and mast cell density. Global Initiative for Chronic Obstructive Lung Disease guidelines were used for defining COPD [17]. All COPD subjects were on relief anticholinergics only. Subjects with other types of respiratory diseases, those with recent exacerbations or who had used systemic or inhalational steroids during the last 12 weeks were excluded. Study subjects had little if any chronic bronchitis.

The study was approved by the human research ethics committee (Tasmania, Australia) network. All subjects provided written informed consent.

Pulmonary function tests were performed according to European Respiratory Society/American Thoracic Society (ATS) guidelines [18]. BDR was defined according to ATS criteria, i.e. an increase of $\geqslant 12 \%$ and $200 \mathrm{~mL}$ from baseline forced expiratory volume in $1 \mathrm{~s}$ (FEV1) after $200 \mu \mathrm{g}$ inhaled salbutamol [7].

Details of bronchoscopies and taking endobronchial biopsies have been described previously [16]. Eight biopsies from segmental bronchi in the right lower lobes were obtained from each individual. No complications were encountered.

\section{Tissue processing}

Of the biopsies, four were fixed in $4 \%$ neutral buffered formalin for $2 \mathrm{~h}$ and subsequently processed into paraffin through graded alcohol and xylene using a Leica (Leica Microsystems, Wetzlar, Germany) ASP 200 tissue processor. $3-\mu \mathrm{m}$ sections were cut from individual paraffin blocks, stained with haematoxylin and eosin and morphologically assessed for suitability for immunostaining, being chosen to minimise tangential sectioning of the epithelium and to provide greatest length of epithelium. Two $3-\mu \mathrm{m}$ sections, separated by a minimum of $50 \mu \mathrm{m}$ from such blocks, were collected on each slide. Following removal of wax and hydration through descending grades of ethanol, sections were immunostained for mast cells using monoclonal mouse anti-human mast cell tryptase antibody (Anti AA1, Dako M7052 (Dako, Cambridge, $\mathrm{UK}), 1$ in 1,500 for $20 \mathrm{~min}$ at $22^{\circ} \mathrm{C}$ ) or monoclonal mouse antihuman chymase (Abcam ab2377 clone CC1 (ABCAM, Cambridge, MA, USA) at $1 / 100$ dilution for $1 \mathrm{~h}$ at $22^{\circ} \mathrm{C}$ ); (all antibodies were diluted using Dako diluent S0809). Serial sections were treated with mouse immunoglobulin G1 isotype control (Dako X0931 at equivalent concentrations and conditions). A positive tissue control was included in all immunostaining. Endogenous peroxidase was quenched using 3\% hydrogen peroxide in water for $15 \mathrm{~min}$ prior to addition of primary antibodies and the sections being stained for mast cell tryptase were treated with $0.025 \%$ type VIII protease (Sigma
P-5380; Sigma-Aldrich, St Louis, MO, USA) in PBS for 3 min at $37^{\circ} \mathrm{C}$ to expose antigens. Subsequent to primary antibodies, Dako EnVision+ (Dako K4001) was applied to the sections for $30 \mathrm{~min}$. The sections were then incubated with diaminobenzidine (Dako) as chromogen for $10 \mathrm{~min}$. For sections stained for mast cell tryptase, immunostaining with monoclonal mouse anti-human von Willebrand factor (Dako M0616; 1/50 for $2 \mathrm{~h}$ at $22^{\circ} \mathrm{C}$ ) was undertaken for vessel staining. This antibody was elaborated using a "Real ${ }^{\mathrm{TM}}$ " (Dako 5005) biotinylated link

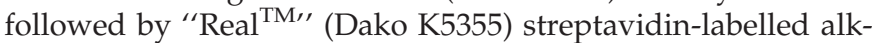
aline phosphatase for $20 \mathrm{~min}$ each. Antibodies were visualised using permanent red (Dako K0640). Mayer's haematoxylin was used to elaborate nuclei and eosin counterstaining was used to discriminate the smooth muscle fibres from surrounding tissue in the immunostained slides.

\section{Measurements}

Sections were randomised and coded independently of the histologist who examined them, blinded to diagnosis and order. Tissue examination was performed using a computer-assisted image analysis tool (Image-Pro version 5.1; Media Cybernetics, Bethesda, MD, USA) at $\times 400$ magnification. As many nonoverlapping pictures as possible were taken from each slide, and eight of these separate fields were randomly chosen for enumeration. Only tissue samples with intact epithelium and basement membrane were selected for examination of the Rbm and LP (fig. 1). As prospective criteria, developed after pilot studies on our material, the amount of smooth muscle available for mast cell analysis had to be sufficient to constitute $30 \%$ of the length immediately below the LP, and to have definite muscle bundles present. In general, this constituted $\sim 0.03 \mathrm{~mm}$ of smooth muscle per slide, which is less than described by BRIGHTLING et al. [3], although the specifics given were somewhat ambivalent.

The number and cross-sectional area of vessels in the Rbm, and separately up to $150 \mu \mathrm{m}$ from the antilumenal border of the

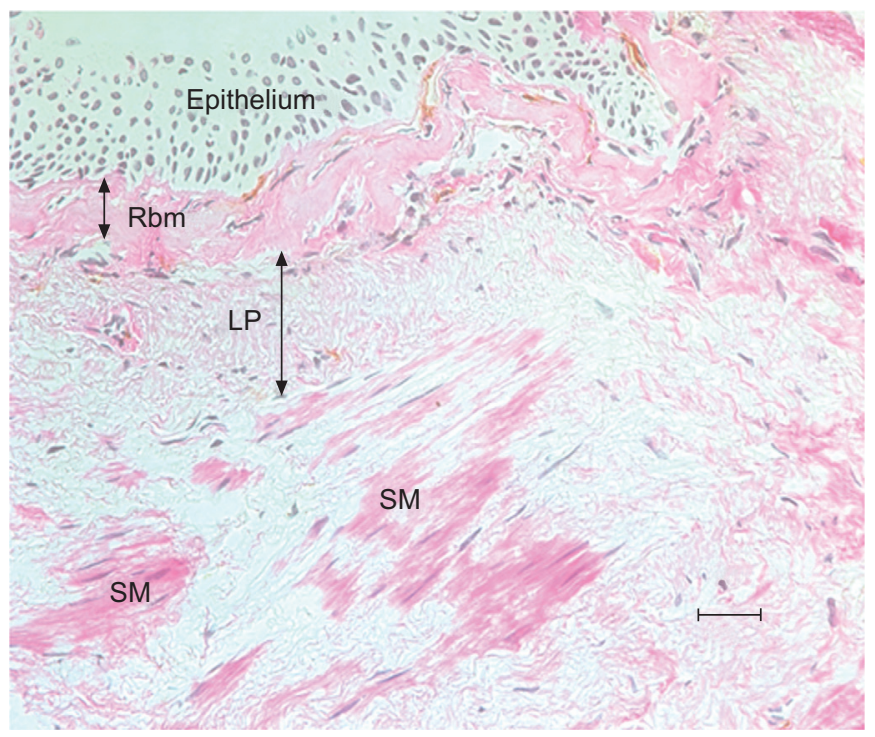

FIGURE 1. A section of a bronchial biopsy to demonstrate the anatomy: epithelium, reticular basement membrane (Rbm), lamina propria (LP) and smooth muscle layer (SM). Haematoxylin and eosin and antitryptase staining, magnification $\times 400$. Scale bar $=20 \mu \mathrm{m}$. 


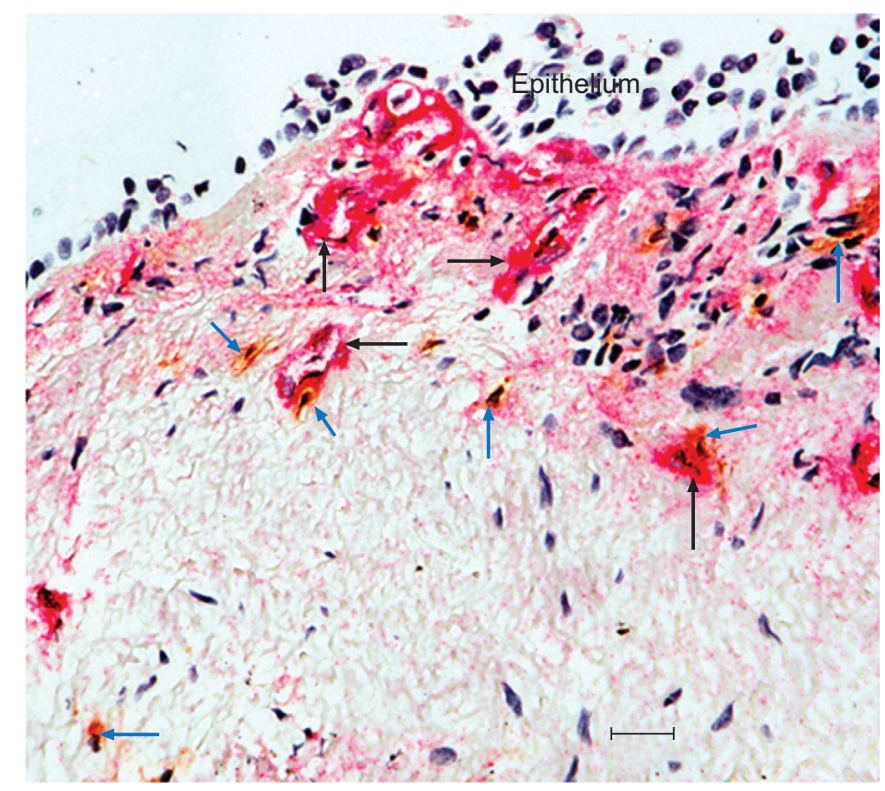

FIGURE 2. A bronchial biopsy stained with anti-factor VIII and anti-tryptase antibodies to detect vessels (black arrows) and mast cells (blue arrows), respectively. Some mast cells are demonstrated around vessels in the lamina propria. Magnification $\times 400$. Scale bar $=20 \mu \mathrm{m}$.

Rbm in the LP (figs 2 and 3), were quantitated and normalised to the length of the Rbm and the area of LP, respectively [16]. As the results corroborated previous observations [16], i.e. hypervascularity in the Rbm and hypovascularity in the LP, these data are not reported. The numbers of tryptase-positive mast cells (MCT) in the Rbm (fig. 3) and the LP (figs 2 and 3) were counted and normalised to the area of the Rbm and LP to calculate the density of mast cells per square millimetre of tissue. The number of MCT and chymase-positive mast cells (MCTC) in the ASM (fig. 4) were counted and divided by the surface area of compartment examined. Using an image analysis tool, a perimeter with a width of $10 \mu \mathrm{m}$ was drawn around the margin of each vessel in the Rbm and LP, and the density of mast cells per square millimetre of tissue in this perimeter compartment was measured. Given the relative size of mast cells (usually $8-10 \mu \mathrm{m}$ in diameter, but up to $20 \mu \mathrm{m}$ ) to the perivascular area of interest, any mast cell that was even partially located within this perimeter or in contact with the perimeter, was counted as being perivascular.

\section{Analysis}

Nonparametric ANOVA (Kruskal-Wallis) tested differences between all study groups, with post hoc analyses for between two groups comparisons performed using Mann-Whitney Utests when analysis revealed a significant difference according to a priori hypothesis. Spearman correlations were used to test relationships. All analyses were performed by PASW statistics 18 (formerly SPSS Inc., Chicago, IL, USA) for Windows. Twotailed p-values $<0.05$ were considered significant.

\section{RESULTS}

60 out of 64 subjects had enough tissue for both the Rbm and LP measurements. 39 out of 49 subjects who were included in the analysis for ASM measurements had adequate tissue per protocol (see Methods section for details). Table 1 shows the

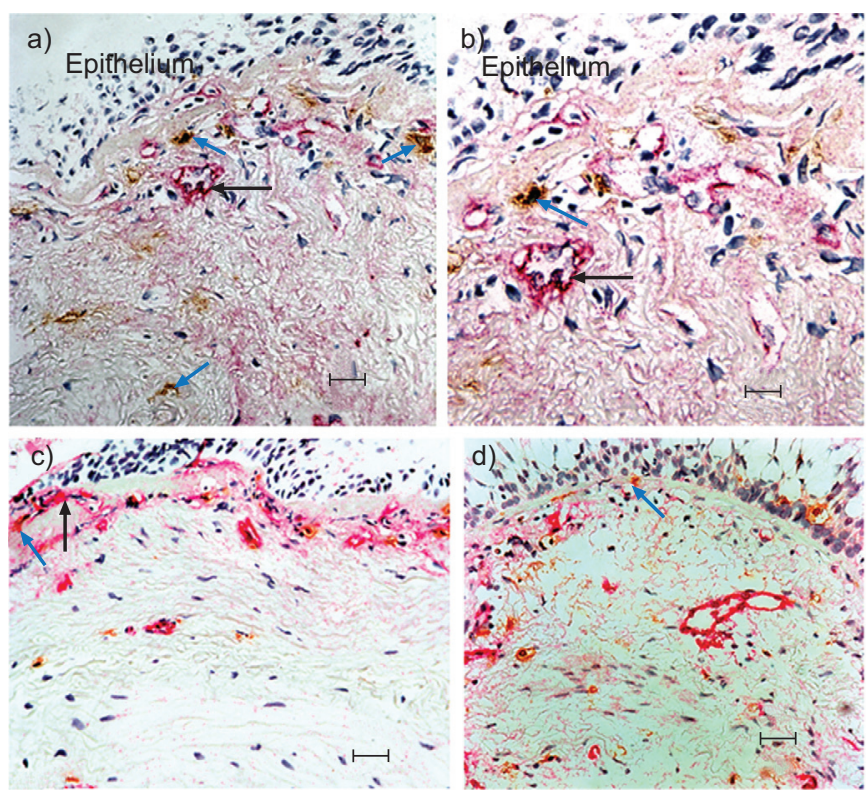

FIGURE 3. Mast cells in the a) and b) lamina propria and c) and d) reticular basement membrane (Rbm). a) Vessels stained by anti-factor VIII antibody (black arrow) and anti-tryptase for mast cells (blue arrows) in the lamina propria. Magnification $\times 400$. b) Higher magnification $(\times 630$ ) of the same area in a). c and d) Mast cells in the Rbm (blue arrows). c) A vessel stained with anti-factor VIII antibody can also be seen in the Rbm (black arrow). Scale bars $=20 \mu \mathrm{m}$.

demographics of the participants. $41 \%$ of S-COPD and $40 \%$ of ES-COPD had BDR according to ATS criteria (41\% overall). $47 \%$ of S-COPD and $69 \%$ of ES-COPD suffered from mild COPD and the rest from moderate COPD (Chi-squared $\mathrm{p}=0.2$ ) [17] . $42 \%$ of COPD with BDR and $67 \%$ of COPD with no BDR had mild disease and the rest had moderate disease (Chisquared $\mathrm{p}=0.2$ ). Median post-bronchodilator change of FEV1 was $250 \mathrm{~mL}$ for all COPD subjects, $340 \mathrm{~mL}$ for COPD with $\mathrm{BDR}$ and $120 \mathrm{~mL}$ for COPD with no BDR.

$65 \%$ of MCT in the ASM layer were stained positively for chymase. The density of ASM layer MCT was not significantly different between COPD with BDR, COPD with no BDR and $\mathrm{H}-\mathrm{N}$ groups (nonparametric ANOVA, $\mathrm{p}=0.8$ ) (fig. 5), and there was no difference in the density of MCTC between COPD with BDR versus COPD with no BDR (median (range) 28 (0-69) versus $47(0-142)$, respectively; $p=0.3)$.

The average density of mast cells and perivascular mast cell density was significantly increased in the Rbm of the S-N, SCOPD and ES-COPD groups compared with H-N (nonparametric ANOVA test $p<0.001$ and $p<0.01$, respectively). S-N had also significantly increased perivascular mast cell density compared with ES-COPD (fig. 6).

The average density of mast cells in the LP was significantly increased in the S-COPD and ES-COPD groups compared with $\mathrm{H}-\mathrm{N}$ (fig. 7). However, the density of perivascular mast cells was not significantly different between groups (fig. 7).

\section{Correlations}

No correlations were found between BDR (either as absolute change or \% change in FEV1) and ASM mast cell density (either $\mathrm{MCT}$ or MCTC) in both COPD groups ( $\mathrm{r}$ values between -0.01 

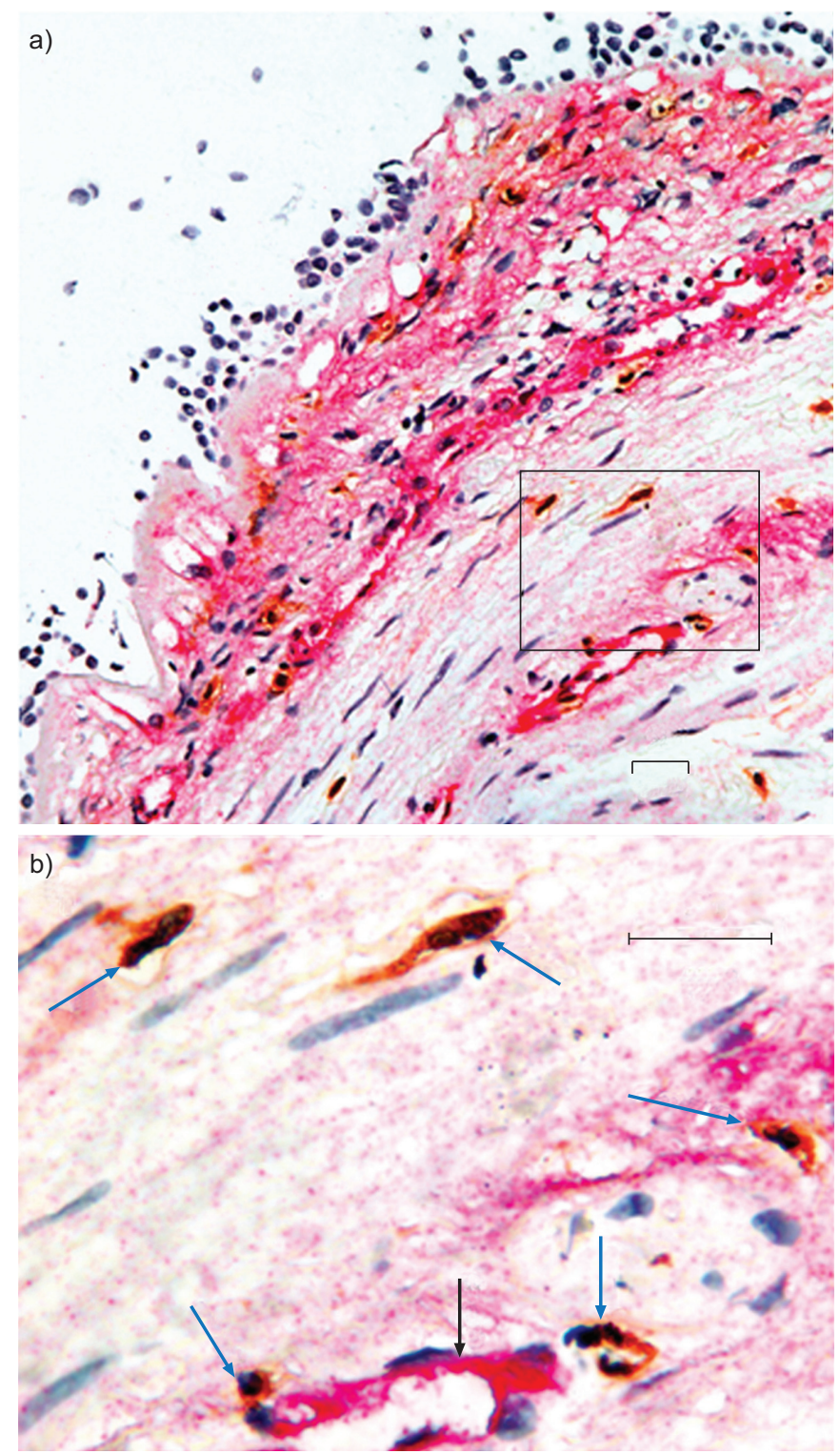

FIGURE 4. Mast cells in airway smooth muscle layer. a) Smooth muscle layer deep in the mucosa in a section of a biopsy of the airway with mast cells stained using the anti-tryptase antibody. Magnification $\times 400$. b) The inset is magnified to show mast cells within the bulk of smooth muscle (blue arrows). A vessel can also be seen (black arrow) stained with anti-factor VIII antibody. Magnification $\times 1000$. Scale bars $=20 \mu \mathrm{m}$.

and -0.3). However, only in the non-BDR COPD group was MCT density in the ASM correlated with FEV1 \% predicted ( $r=0.5$, $\mathrm{p}<0.05$ ), and MCTC density in the ASM was correlated quite strongly and positively with forced vital capacity (FVC) $(r=0.8$, $\mathrm{p}<0.01)$ and FVC \% predicted $(\mathrm{r}=0.7, \mathrm{p}<0.05)$, and correlated negatively with the FEV1/FVC ratio $(r=-0.6, p<0.05)$.

Perivascular mast cell density in the Rbm correlated positively with number and area of vessels in S-COPD $(\mathrm{r}=0.8, \mathrm{p}<0.01$ and $r=0.7, p<0.01$ for number and area of vessels, respectively), in ES-COPD $(r=0.7, p<0.05$ and $r=0.6, p<0.05)$ and in the S-N groups $(r=0.8, p<0.01$ and $r=0.9, p<0.001)$. Total mast cell density (but not perivascular density) in the LP correlated

\section{TABLE 1 Demographics}

\begin{tabular}{|c|c|c|c|c|}
\hline Groups & $\mathrm{H}-\mathrm{N}$ & S-N & S-COPD & ES-COPD \\
\hline Subjects $n$ & 17 & 15 & 17 & 15 \\
\hline Age $^{*}$ yrs & 49 (20-68) & $46(30-65)$ & $60(46-69)$ & 61 (53-69) \\
\hline Female/male & $11 / 6$ & $4 / 11$ & $7 / 10$ & $5 / 10$ \\
\hline $\begin{array}{l}\text { Pack-yrs } \\
\text { smoking }\end{array}$ & 0 & $35(11-57)$ & 44 (18-82) & $50(18-151)$ \\
\hline $\mathrm{FEV}_{1} / \mathrm{FVC}^{\#} \%$ & $82(71-88)$ & 78 (70-96) & 59 (46-68) & $62(38-68)$ \\
\hline FEV $_{1} \%$ pred & $107(86-140)$ & $93(78-125)$ & $79(55-100)$ & $83(55-112)$ \\
\hline$\Delta \mathrm{FEV}_{1} \%$ & & & $8(0-30)$ & $10(2-17)$ \\
\hline
\end{tabular}

Data are presented as median (range), unless otherwise stated. $\mathrm{H}-\mathrm{N}$ : healthy and nonsmoking controls; S-N: smokers with normal lung function; S-COPD: smokers with chronic obstructive pulmonary disease; ES-COPD: ex-smokers with COPD; FEV1: forced expiratory volume in $1 \mathrm{~s}$; FVC: forced vital capacity; \% pred: \% predicted. * : post-bronchodilator values. *: $p<0.05$ (nonparametric ANOVA).

negatively with the area of vessels in this compartment only in the S-COPD group $(\mathrm{r}=-0.5, \mathrm{p}<0.05)$. Age was on average greater in the COPD groups, although with substantial overlap with the other groups. Furthermore, there was no suggestion of a relationship between age (either within groups or for the whole dataset), and any variables of interest in our study (as examples, in both COPD groups combined, for age versus Rbm mast cells, $\mathrm{r}=-0.02, \mathrm{p}=0.9$; for age versus LP mast cells, $\mathrm{r}=-0.2$, $\mathrm{p}=0.4)$.

\section{DISCUSSION}

Our main airway pathophysiological findings can be summarised as follows.

First, there was no relation between mast cell density in the ASM in COPD subjects and variation in BDR for either tryptase

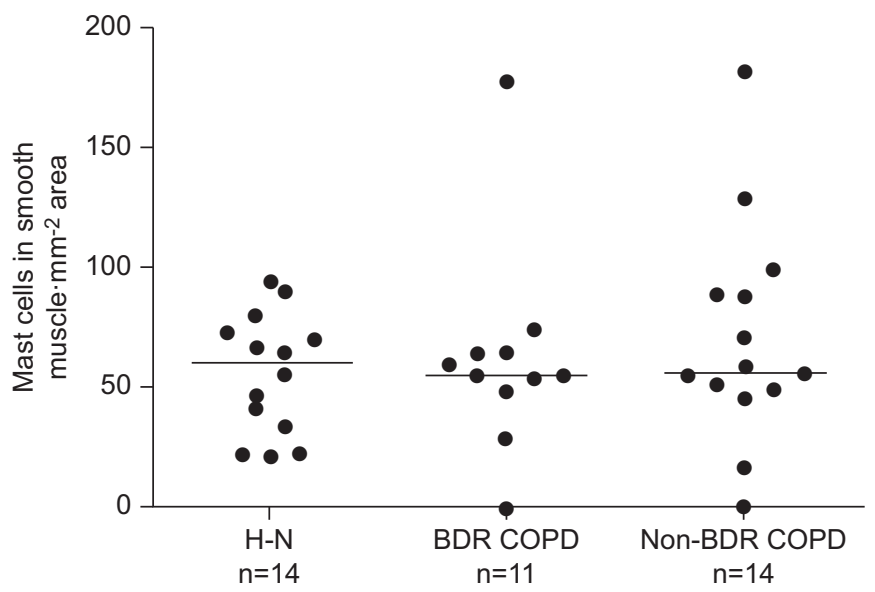

FIGURE 5. Smooth muscle mast cell density with no difference between groups (nonparametric ANOVA, $\mathrm{p}=0.8$ ). Bars indicate medians. $\mathrm{H}-\mathrm{N}$ : healthy nonsmokers; BDR: bronchodilator responsiveness; COPD: chronic obstructive pulmonary disease. 

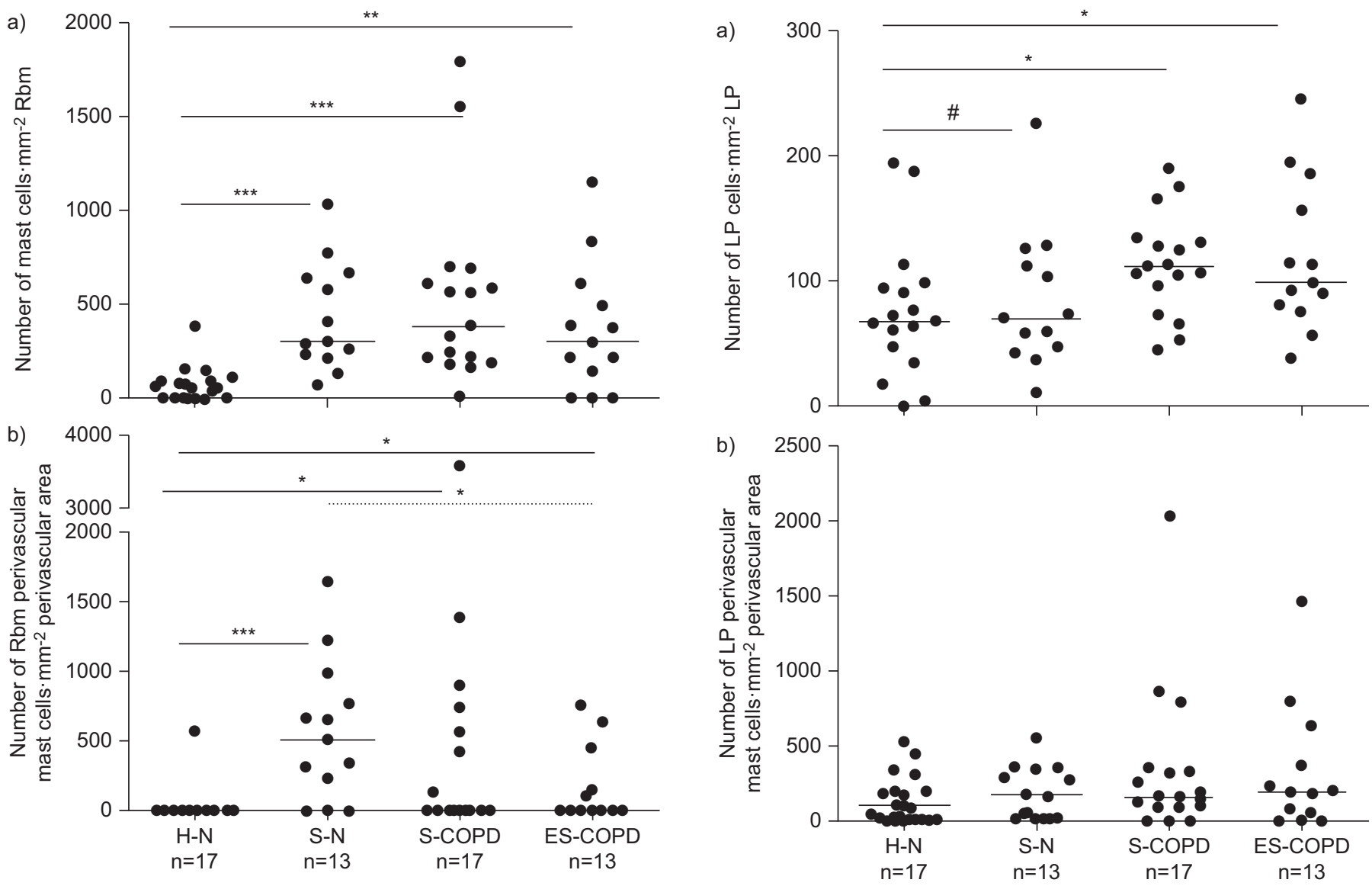

FIGURE 6. Reticular basement membrane (Rbm) mast cells: density of cells a) generally in the Rbm and b) specifically in the perivascular area. Bars indicate medians. H-N: healthy nonsmokers; S-N: smokers with normal lung function; SCOPD: smokers with chronic obstructive pulmonary disease; ES-COPD: exsmokers with COPD. ${ }^{*}: p<0.05 ;{ }^{* *}: p<0.01 ; * * *: p<0.001$.

or chymase cellular subtypes. Secondly, increased perivascular mast cell density in the $\mathrm{Rbm}$, found especially in current smokers, was positively related to Rbm hypervascularity. Thirdly, average mast cell density in the hypovascular LP was increased in both COPD groups compared with the control group, but not in normal smokers; however, perivascular mast cell density was not different between groups, and was not related to vessel number in the LP. Fourthly, in COPD subjects without BDR, there was a positive relationship between mast cell density and better airway function.

Some studies have reported "asthmatic features" in a subgroup of COPD patients and suggested an overlapping asthma phenotype [9-11]. However, in contrast to the findings in asthma suggesting localisation of mast cells in the smooth muscle [15], our study found no differential localisation of mast cells in the ASM layer in COPD, and localisation was not found specifically in those with more BDR, at least not in those large airway biopsies under investigation. In general, airway pathology is uniform throughout the airway system [19] and it is unlikely that BDR is solely a small airway function, even in COPD. We feel that the findings do suggest that the pathophysiology of BDR is different between asthma and COPD, though it would be reassuring to also have a repeat

FIGURE 7. Lamina propria (LP) mast cells: density of cells a) generally in the LP and b) perivascular density. Perivascular mast cells were not different between groups (nonparametric ANOVA, $\mathrm{p}=0.6$ ). Bars indicate medians. $\mathrm{H}-\mathrm{N}$ : healthy nonsmokers; $\mathrm{S}-\mathrm{N}$ : smokers with normal lung function; S-COPD, smokers with chronic obstructive pulmonary disease; ES-COPD: ex-smokers with COPD. ${ }^{*}$ : $p=0.07 .{ }^{*}: p<0.05$.

pathophysiological correlation study involving small airway tissue, though of course this would be logistically difficult.

There is a close relationship between BHR and BDR in asthma [6], and they are likely to be related entities. This relationship has also been shown in COPD, where baseline airway calibre is less variable than asthma [14]. Similarly, REID et al. [8] did not find any particular asthma-type eosinophilic inflammatory feature which could differentiate COPD with BDR from COPD with no BDR. Our findings are in keeping with other studies that found no changes in ASM mast cells in COPD [20-22] and no correlation between ASM mast cell number and BHR [22].

It has been shown that BDR is variable over time in COPD subjects [23]. Bronchodilator reversibility and endobronchial airway biopsies were performed within $24 \mathrm{~h}$ in our subjects, and we feel it is reasonable to use our data from these two procedures as representing a single epoch. It is unlikely that the cellular or physiological picture would be very different over $24 \mathrm{~h}$ in stable subjects with no change in clinical or therapeutic status.

ASM mast cell densities, determined with both tryptase and chymase staining, were correlated positively with lung function 
parameters. GOSMAN et al. [24] also found a similar positive correlation between ASM mast cell density in small airways and FEV1 \% predicted, but they also found a positive correlation between peripheral airway epithelial and subepithelial mast cell density and the FEV1/FVC ratio. Overall, these data suggest that mast cells are protective to the airways in COPD, or that they are found particularly in earlier disease.

Our study revealed that perivascular mast cell density in the Rbm was positively associated with the number and area of vessels in that compartment, suggesting that mast cells may play a role in angiogenesis and hypervascularity in the bronchial Rbm in both smokers and COPD subjects. Our previous report of increased vessel-associated VEGF in the $\mathrm{Rbm}$ is compatible with this suggestion [16]. In the LP where vessel numbers were decreased, overall mast cell density was increased, but interestingly this was not the case in the perivascular space, where they were relatively decreased compared with the rest of the LP. We did find a negative correlation between overall mast cell density and vascular area, and future studies should investigate whether these cells may be secreting anti-angiogenic factors [1].

Previous data on mast cells in COPD airways have given mixed messages, but none have deliberately differentiated between Rbm and LP compartments. GRASHOFF et al. [25] studied small airways from current- and ex-smokers with COPD and reported more mast cells in the epithelium, but not in the remainder of the airway wall. However, a group in Sweden found more mast cells in the epithelium, LP and ASM in biopsies taken from the main tracheal carina in asymptomatic smokers [26]. Others have not found an increase in airway mast cells in COPD, but used smokers with or without bronchitis as controls [27, 28]. Other studies that have found no difference in mast cell numbers between S-COPD and S-N have had very small numbers of participants, with the possibility of type-2 statistical errors [29, 30].

Although our COPD subjects were generally older than those in the $\mathrm{H}-\mathrm{N}$ and S-N groups, there was great overlap, and no suggestions of relationships between age and the outcomes of interest in this study, either in the whole dataset or in any subgroups. From 32 COPD subjects, only 25 had enough appropriate tissue (as per prospective protocols) for comparing ASM mast cell density between groups. This could raise a question about the power of the study, but figure 5 makes it clear that a type-2 statistical error is quite unlikely.

\section{Conclusions}

Our study did not find the "asthma-type" picture of disproportionately more mast cell in the ASM layer in bronchial biopsies from the subgroup of COPD with BDR. Perivascular mast cell density was increased in the hypervascular Rbm in both the S-N and COPD groups, though it was predominantly a smoking-related effect. Mast cells were increased in number in the LP in COPD groups, but not in physiologically normal smokers, and were relatively fewer around the numerically depleted LP vessels. Our novel data suggest roles for mast cells in vascular airway remodelling in COPD, and potentially in preservation of airway function.

\section{SUPPORT STATEMENT}

This study was supported by a NHMRC Australia project grant and the Royal Hobart Hospital Research Foundation through a Sypkes Fellowship.

\section{STATEMENT OF INTEREST}

None declared.

\section{REFERENCES}

1 Norrby K. Mast cells and angiogenesis. APMIS 2002; 110: 355-371.

2 Brightling CE, Bradding P, Pavord ID, et al. New insights into the role of the mast cell in asthma. Clin Exp Allergy 2003; 33: 550-556.

3 Brightling CE, Bradding P, Symon FA, et al. Mast-cell infiltration of airway smooth muscle in asthma. N Engl J Med 2002; 346: 1699-1705.

4 Zanini A, Chetta A, Saetta M, et al. Chymase-positive mast cells play a role in the vascular component of airway remodeling in asthma. J Allergy Clin Immunol 2007; 120: 329-333.

5 Ibaraki T, Muramatsu M, Takai S, et al. The relationship of tryptase- and chymase-positive mast cells to angiogenesis in stage I non-small cell lung cancer. Eur J Cardiothorac Surg 2005; 28: 617-621.

6 Parker AL. Airway reactivity is a determinant of bronchodilator responsiveness after methacholine-induced bronchoconstriction. J Asthma 2004; 41: 671-677.

7 Reid DW, Soltani A, Johns DP, et al. Bronchodilator reversibility in Australian adults with chronic obstructive pulmonary disease. Intern Med J 2003; 33: 572-577.

8 Reid DW, Yudong WEN, David PJ, et al. Bronchodilator reversibility, airway eosinophilia and anti-inflammatory effects of inhaled fluticasone in COPD are not related. Respirology 2008; 13: 799-809.

9 Chanez P, Vignola AM, O'Shaugnessy T, et al. Corticosteroid reversibility in COPD is related to features of asthma. Am J Respir Crit Care Med. 1997; 155: 1529-1534.

10 Fujimoto K, Kubo K, Yamamoto H, et al. Eosinophilic inflammation in the airway is related to glucocorticoid reversibility in patients with pulmonary emphysema. Chest 1999; 115: 697-702.

11 Brightling CE, McKenna S, Hargadon B, et al. Sputum eosinophilia and the short term response to inhaled mometasone in chronic obstructive pulmonary disease. Thorax 2005; 60: 193-198.

12 Anthonisen NR, Connett JE, Kiley JP, et al. Effects of smoking intervention and the use of an inhaled anticholinergic bronchodilator on the rate of decline of FEV1. JAMA 1994; 272: 1497-1505.

13 Li Q, Xie G, Cheng X. The relationship between bronchial hyperresponsiveness and chronic obstructive pulmonary disease. Zhonghua Jie He He Hu Xi Za Zhi 2001; 24: 584-587.

14 Campbell AH, Barter CE, $\mathrm{O}^{\prime}$ Connell JM, et al. Factors affecting the decline of ventilatory function in chronic bronchitis. Thorax 1985; 40: 741-748.

15 Siddiqui S, Hollins F, Saha S, et al. Inflammatory cell microlocalisation and airway dysfunction: cause and effect? Eur Respir J 2007; 30: 1043-1056.

16 Soltani A, Reid D, Sohal S, et al. Basement membrane and vascular remodelling in smokers and chronic obstructive pulmonary disease: a cross-sectional study. Respir Res 2010; 11: 105.

17 Global Initiative for Chronic Obstructive Pulmonary Disease. Global Strategy for the Diagnosis, Management and Prevention of COPD, Global Initiative for Chronic Obstructive Lung Disease (GOLD) 2011. www.goldcopd.org. Date last accessed: April 6, 2012.

18 Miller MR, Hankinson J, Brusasco V, et al. Standardisation of spirometry. Eur Respir J 2005; 26: 319-338.

19 Ward C, Snell GI, Orsida B, et al. Airway versus transbronchial biopsy and BAL in lung transplant recipients: different but complementary. Eur Respir J 1997; 10: 2876-2880. 
20 Baraldo S, Turato G, Badin C, et al. Neutrophilic infiltration within the airway smooth muscle in patients with COPD. Thorax 2004; 59: 308-312.

21 Saha S, Mistry V, Siva R, et al. Induced sputum and bronchial mucosal expression of interleukin-13 is not increased in chronic obstructive pulmonary disease. Allergy 2008; 63: 1239-1243.

22 Liesker JJW, ten Hacken NHT, Rutgers SR, et al. Mast cell numbers in airway smooth muscle and PC20AMP in asthma and COPD. Respir Med 2007; 101: 882-887.

23 Calverley PMA, Burge PS, Spencer S, et al. Bronchodilator reversibility testing in chronic obstructive pulmonary disease. Thorax 2003; 58: 659-664.

24 Gosman M, Postma D, Vonk J, et al. Association of mast cells with lung function in chronic obstructive pulmonary disease. Respir Res 2008; 9: 64 .

25 Grashoff WF, Sont JK, Sterk PJ, et al. Chronic obstructive pulmonary disease: role of bronchiolar mast cells and macrophages. Am J Pathol 1997; 151: 1785-1790.
26 Amin K, Ekberg-Jansson A, Lofdahl CG, et al. Relationship between inflammatory cells and structural changes in the lungs of asymptomatic and never smokers: a biopsy study. Thorax 2003; 58: $135-142$.

27 Di Stefano A, Turato G, Maestrelli P, et al. Airflow limitation in chronic bronchitis is associated with T-lymphocyte and macrophage infiltration of the bronchial mucosa. Am J Respir Crit Care Med 1996; 153: 629-632.

28 Saetta M, Turato G, Facchini Fabrizio M, et al. Inflammatory cells in the bronchial glands of smokers with chronic bronchitis. Am J Respir Crit Care Med 1997; 156: 1633-1639.

29 O'Shaughnessy TC, Ansari TW, Barnes NC, et al. Inflammation in bronchial biopsies of subjects with chronic bronchitis: inverse relationship of CD8+ T lymphocytes with FEV1. Am J Respir Crit Care Med 1997; 155: 852-857.

30 Saetta M, Di Stefano A, Maestrelli P, et al. Activated Tlymphocytes and macrophages in bronchial mucosa of subjects with chronic bronchitis. Am Rev Respir Dis 1993; 147: 301-306. 